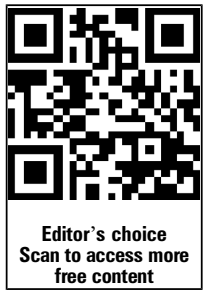

${ }^{1}$ Department of Health Policy

School of Public Health, Boston,

Massachusetts, USA

${ }^{2}$ Department of Medicine, Harvard Medical School,

Mongan Institute for Health

Policy, Massachusetts General

Hospital, Boston, Massachusetts, USA

${ }^{3}$ Brandeis International Business School, Waltham,

Massachusetts, USA

\section{Correspondence to}

Dr Sara I Singer, Department of Health Policy and Management, Harvard School of Public Health, 677 Huntington Avenue,

Kresge 3, Room 317, Boston,

MA 02115, USA

ssinger@hsph.harvard.edu

Received 24 July 2014 Accepted 24 July 2014

\section{SLinked}

http://dx.doi.org/10.1136/ bmjqs-2012-001706

- http://dx.doi.org/10.1136/ bmjqs-2014-002831

- http://dx.doi.org/10.1136/ bmjqs-2013-002042

\section{CrossMark}

To cite: Singer SJ, Tucker AL. BMJ Qual Saf 2014;23:

789-800.

\title{
The evolving literature on safety WalkRounds: emerging themes and practical messages
}

Sara J Singer, ${ }^{1,2}$ Anita L Tucker ${ }^{3}$

\section{THE ROAD TO WALKING AROUND}

The evidence is clear: a strong culture of safety is necessary to deliver reliably safe care. ${ }^{1}$ Safety culture encompasses a group's shared values, assumptions, attitudes and patterns of behaviour regarding safety. $^{2}{ }^{3}$ In healthcare organisations with weak safety culture, employees perceive the low priority assigned to safety, and patient safety suffers as a result. ${ }^{4}$ Researchers measure safety culture using surveys that include items eliciting perceptions of policies, procedures and practices that reflect the extent to which the organisation prioritises safety relative to competing goals. ${ }^{4}$

Numerous studies find that higher safety climate correlates with better performance on a variety of outcomes. ${ }^{1}{ }^{5-17}$ Research also shows that senior managers play a critical role in creating, changing and sustaining safety culture. ${ }^{2}{ }^{4}$ Senior managers' words and deeds receive outsize attention and greatly influence how frontline workers and middle managers perceive what their organisation values and rewards.

We know less, though, about specific actions senior managers can take to effectively demonstrate their commitment to safety. ${ }^{18}$ Senior managers seeking to create a stronger culture of safety need to know what steps can overcome consistent differences between frontline workers' and managers' perceptions of safety climate. Frontline workers typically have more negative views of safety climate compared with senior managers. ${ }^{19-21}$

One approach for strengthening safety culture is for managers to spend time on the frontlines of care, talking with staff and observing work. The Lean literature refers to these types of programmes as Gemba walks. ${ }^{22}$ These walks aim to have senior managers observe concrete problems confronted by frontline staff in real time and foster stronger relationships with frontline staff. $^{23} 24$ Gemba walks thus resemble 'Management by Walking Around,' popularised by Peters and Waterman's description of Hewlett-Packard's use of the programme in the 1980s. ${ }^{25}$

A similar approach appeared in healthcare as early as $1990,{ }^{26}$ but did not receive widespread attention until the publication of Frankel and colleagues' work on Patient Safety Leadership WalkRounds. This programme sought to raise senior managers' commitment to patient safety. ${ }^{2324}{ }^{27}$ Based on its success, safety rounds of this type have been advocated by leading healthcare organisations, including the Institute for Healthcare Improvement, ${ }^{28}$ Agency for Healthcare Research and Quality, and Health Research and Educational Trust in the USA; and the National Health System $^{29}$ and the Scottish Patient Safety Programme in the UK.

We will use the generic term 'safety rounds' to refer to all programmes. Safety rounds aim to improve care by providing a systematic approach for engaging senior managers with the work-system challenges faced by frontline staff and ensuring follow-up and accountability for addressing these challenges. Safety rounds encourage senior managers to observe clinical operations, engage with staff to understand their concerns and partner with frontline workers and managers to resolve obstacles. Safety rounds offer opportunities to fix specific problems identified but also to improve safety culture more generally by building trust, understanding and accountability for safety up and down the organisational hierarchy. ${ }^{24}$

As of 2014, safety rounds have been implemented by thousands of hospitals worldwide. ${ }^{i}$ Drawing on a handful of

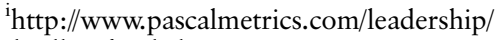
dr-allan-frankel/ 
publications about safety rounds programmes, reviews of interventions with potential to improve safety culture and patient safety 3031 describe safety rounds as one of the most evidence-based safety interventions used in practice. An emerging literature about safety rounds programmes, including papers recently published in this journal, ${ }^{32} 33$ presents an opportunity to review in more detail what has been learned so far about this promising programme and how interested managers can successfully implement safety rounds in their own organisations.

\section{THE EXPANDING LITERATURE ON SAFETY ROUNDS}

In preparing this editorial cum review, we searched PubMed using the terms 'walkround', 'walk round', 'walkaround', 'walkabout', 'Gemba', 'safety rounds [and] senior management' and 'leadership round'. We identified 93 articles published since Frankel and colleagues' 2003 publication that first drew attention to the implementation of safety rounds in healthcare. ${ }^{24}$ After eliminating articles that simply mentioned safety rounds and adding some more articles identified through searches of references, we found 43 studies of safety rounds. The authors each reviewed these papers to identify common themes. We then assigned each paper to themes for which the paper was relevant, noting the paper's findings. (Table 1 presents a complete list of these articles and their key findings).

\section{TECHNIQUE FOR IMPROVING SAFETY CULTURE}

The vast majority of papers report qualitative results from a self-selected implementation of safety rounds in a single or small number of hospitals. Three-quarters of the papers that we review (33 out of 43) report that safety rounds have a positive impact on their organisations. These papers typically state that safety rounds had a beneficial impact on senior managers' beliefs and problem-solving activities. For example, safety rounds are credited with heightening awareness of and insight about safety issues among senior managers. ${ }^{24}$ 34-38 These issues include ones previously unknown, overlooked or presumed resolved by senior managers. ${ }^{39}$ The novel information increases senior managers' support for patient safety improvement efforts. ${ }^{24}$ Consequently, safety rounds enable hospitals to identify and eliminate safety hazards ${ }^{27} \quad 36-38 \quad 40-43$ and improve hospital efficiency. 394445 They also allow senior managers to demonstrate that safety is a priority. ${ }^{18} 374046$ Finally, frontline workers who participate in safety rounds feel more willing to be open about patient safety issues ${ }^{38}$ and more recognised, and they experience improved morale. ${ }^{35-37}$ These papers demonstrate 'proof of concept' by using case studies of successful implementations of safety rounds to show that (1) it is feasible for senior managers to maintain a rigorous implementation of safety rounds; (2) safety rounds enable senior managers to identify meaningful safety concerns and (3) if hospitals address these concerns, staff satisfaction with safety climate can increase.

\section{MEANS OF ADDRESSING SAFETY PROBLEMS NOT OTHERWISE IDENTIFIED}

A number of papers describe the types of issues identified through safety rounds programmes. Infrastructure problems (eg, equipment, supplies, work environment and facility concerns such as insufficient lighting or trip hazards) are among the most frequent issues identified through safety rounds. ${ }^{35} 38394447-5271$

Investigators note that infrastructure issues identified through safety rounds pose safety risks and diminish staff efficiency, but can usually be easily fixed. ${ }^{44}$ Furthermore, safety rounds are an important component of an organisation's portfolio of safety initiatives because the types of issues they uncover are often not highlighted through other safety systems, such as incident reports. ${ }^{38} 4753$ The issues are also not identified through national initiatives, ${ }^{44}$ which tend to focus on implementing evidence-based practices, such as reducing catheter-related blood stream infections. Therefore, safety rounds provide value by uncovering significant and actionable items that might otherwise remain unresolved. ${ }^{384447485053}$

\section{CAUTIONARY NOTES}

Limitations of safety rounds as a tool for improving safety culture

A potential limitation of safety rounds is that issues commonly implicated in medical errors and near-miss incidents are less frequently raised through safety rounds than are infrastructure-related issues. ${ }^{3} 32$ Examples of issues that contribute to errors and incidents, but are less frequently mentioned in safety rounds include complex or potentially contentious communication, 27354044474950 especially interdisciplinary communication challenges, ${ }^{27} 41 \quad 4454$ care delivery issues, such as difficulty accessing electronic information in support of clinical decision making, ${ }^{49}$ and opportunities for staff education. ${ }^{50}$ Thus, a risk of embarking on a programme of safety rounds is that the programme might expose mostly minor issues, while other significant problems remain latent. Furthermore, senior managers may be tempted to disregard the majority of issues identified in favour of a small subset most directly related to medical errors. ${ }^{32}$ Senior managers may also hesitate to address infrastructure issues when they involve significant financial resources. When senior managers do not address issues raised by frontline staff, safety rounds can cause frustration among frontline workers, worsen perceptions of safety climate and potentially negatively impact their attention to patient safety, ${ }^{32} 55$ as we discuss in more detail below. 
Table 1 Literature on safety rounds

\begin{tabular}{|c|c|c|c|}
\hline Reference & Objectives & Methods & Findings \\
\hline Frankel et al 2003 & $\begin{array}{l}\text { To describe a patient safety advisory and leaders group } \\
\text { programme developed in one large, integrated healthcare } \\
\text { delivery system in the Boston, Massachusetts, area. }\end{array}$ & Descriptive; case study. & $\begin{array}{l}\text { Implemented safety rounds as key milestone of the } \\
\text { programme. This, and related efforts, have heightened } \\
\text { awareness of patient safety, especially among hospital senior } \\
\text { leaders, which has resulted in substantial support for patient } \\
\text { safety initiatives. }\end{array}$ \\
\hline Pronovost et al 2004 & $\begin{array}{l}\text { To describe a safety programme at the Johns Hopkins Hospital } \\
\text { in which senior hospital executives each adopted an intensive } \\
\text { care unit and worked with the unit staff to identify issues, and } \\
\text { to empower staff to address safety issues. }\end{array}$ & Descriptive; case study. & $\begin{array}{l}\text { The senior executive adopt-a-work unit programme was } \\
\text { successful in identifying and eliminating hazards to patient } \\
\text { safety and in creating a culture of safety. }\end{array}$ \\
\hline Anonymous 2005 & $\begin{array}{l}\text { To describe the safety rounds programmes at } \\
\text { Newton-Wellesley Hospital (Newton, MA) and Marian Hospital } \\
\text { (Carbondale, PA), at which rounds were conducted by the } \\
\text { Director of Legal Affairs. }\end{array}$ & Descriptive. & $\begin{array}{l}\text { Safety rounds have identified the importance of problems } \\
\text { thought to be small. They provide information based on which } \\
\text { unit managers can act. }\end{array}$ \\
\hline Budrevics and O'Neill 2005 & $\begin{array}{l}\text { To describe in detail the safety rounds programme at } \\
\text { Sunnybrook \& Women's College Health Science Centre in } \\
\text { Canada. }\end{array}$ & Descriptive, case study. & $\begin{array}{l}\text { Taking steps to prepare, set expectations, and build trust } \\
\text { among all the participants enables meaningful dialogue that } \\
\text { was open and honest. Environmental gaps and ageing facility } \\
\text { infrastructure issues were most frequently identified. }\end{array}$ \\
\hline Frankel et al 2005 & $\begin{array}{l}\text { To describe the experience of four hospitals (Brigham and } \\
\text { Women's and three others) with safety rounds. }\end{array}$ & Descriptive; multiple case study; interviews. & $\begin{array}{l}\text { In } 28 \text { months, } 233 \text { one-hour safety rounds yielded } 1,433 \\
\text { comments; } 30 \% \text { related to equipment, } 13 \% \text { to } \\
\text { communications, } 7 \% \text { to pharmacy, and } 6 \% \text { to workforce. } \\
\text { Implementation feasibility featured more prominently than } \\
\text { severity in determining actions. }\end{array}$ \\
\hline Gandhi et al 2005 & $\begin{array}{l}\text { Based on experience with safety rounds and other reporting } \\
\text { systems at Brigham and Women's Hospital (Boston), to discuss } \\
\text { the importance of follow-up and feedback and describe an } \\
\text { information-tracking database. }\end{array}$ & Descriptive. & $\begin{array}{l}\text { Developing and maintaining a systematic method for feedback } \\
\text { represents more of a challenge than the completion of any } \\
\text { single recommended action item, yet feedback perpetuates the } \\
\text { influx of information and closes the loop. Maintaining the } \\
\text { information-tracking database requires significant effort, but } \\
\text { has made providing feedback easier and more reliable. }\end{array}$ \\
\hline Graham et al 2005 & $\begin{array}{l}\text { To describe Kaiser Permanente's experience with safety rounds } \\
\text { in two pilot sites. }\end{array}$ & Descriptive; multiple case study. & $\begin{array}{l}\text { Safety rounds created a remarkable change in the patient } \\
\text { safety culture at the participating medical centers. }\end{array}$ \\
\hline Thomas et al 2005 & $\begin{array}{l}\text { To measure the impact of safety rounds on non-clinician } \\
\text { provider attitudes about the safety climate in } 23 \text { clinical units } \\
\text { of one tertiary care teaching hospital. }\end{array}$ & $\begin{array}{l}\text { Quantitative: survey, pre and post with randomized } \\
\text { controlled design. }\end{array}$ & $\begin{array}{l}\text { After safety rounds, the mean safety climate scores were not } \\
\text { significantly different for all providers, nor for nurses in the } \\
\text { control units and safety round units. However, nurses in the } \\
\text { control group who did not participate in safety rounds had } \\
\text { lower safety climate scores than nurses in the intervention } \\
\text { group who did participate in a safety round session. }\end{array}$ \\
\hline Beil-Hildebrand 2006 & $\begin{array}{l}\text { To describe the implications of safety rounds on healthcare } \\
\text { employees in one German hospital. }\end{array}$ & $\begin{array}{l}\text { Descriptive; in-depth case study in the hospital's nursing } \\
\text { division. }\end{array}$ & $\begin{array}{l}\text { Safety rounds were used as a means of managerial control } \\
\text { and, as such, the positive vision for safety rounds was met } \\
\text { with skepticism and cynicism. }\end{array}$ \\
\hline Feitelberg 2006 & $\begin{array}{l}\text { To describe the safety rounds programme in the Kasier } \\
\text { Permanente San Diego Service Area. }\end{array}$ & Descriptive, case study. & $\begin{array}{l}\text { The safety rounds programme plays a major part in promoting } \\
\text { responsible identification and reporting of patient safety issues. }\end{array}$ \\
\hline
\end{tabular}




\begin{tabular}{ll}
\hline Reference & Objectives \\
\hline Richardson et al 2007 & To describe a safety rounds pilot project at Children's Hospital
\end{tabular}

To describe a safety rounds pilot project at Children's Hospita
of Eastern Ontario that built on success factors identified in the literature.

Verschoor et al 2007

To describe the implementation and adaptation of safety rounds and other tools recommended by the Institute for Healthcare Improvement, at Children's' and Women's Health Centre of British Columbia.

Burnett et al $2008 \quad$ To describe the complex social processes underpinning safety rounds in 20 organisations participating in Phase 2 of the UK NHS Safer Patients Initiative.

Donnelly et al $2008 \quad$ To describe a safety rounds programme in a department of radiology, in which radiology leaders' visit imaging divisions at the site of imaging and discuss frontline employees' concerns.

Elder et al 2008

To explore perceptions of patient safety among nursing staff in ICUs following participation in a safety project that decreased hospital-acquired infections.

To describe the experience of implementing safety rounds in four hospitals.

Frankel et al 2008

To describe and evaluate the impact of rigorous safety rounds on frontline caregiver assessments of safety climate in seven hospitals.

Matlow et al 2008

To describe the Blueprint for Patient Safety surveillance programme, which includes safety rounds as one part of a four-part approach to identify potential and existing

vulnerabilities and failures and put measures in place to avoid and mitigate any harm, at the Hospital for Sick Children, and to discuss successes and challenges.

Montgomery 2008

To describe a staff-led safety round approach at Kosair Children's Hospital in Louisville, $\mathrm{KY}$.
Methods

Findings

Descriptive with online survey to solicit staff suggestions and support for safety rounds.

Descriptive, case study.

Qualitative analysis of 56 interviews, using an inductive approach and then a thematic analysis.

Descriptive, case study.

Mixed methods: including comparison of data from focus groups with 33 nurses, cross-sectional safety climate surveys with nurses and managers, and categories represented in safety checklists used on the safety rounds at three hospitals.

Descriptive.

Quantitative: survey with pre and postanalysis.

Descriptive, case study.

Descriptive, case study.
After 19 rounds, participants identified 181 issues, mostly related to organisational/management and work environment. Among 24\% of staff responding, most supported rounds. Barriers included need for additional education and time and infrastructure for complex change.

Adaptations included longer discussions with more than one staff members. Discussions were Non-punitive in orientation.

Safety rounds can help executives to learn about their organisation, leadership style and attitudes.

Multiple patient safety and other issues have been identified and remedied. The authors believe that safety rounds have improved patient safety, quality of care, and efficiency of operations. The mean number of days between serious safety events involving radiology has doubled since programme inception.

Less than half (47\%) the patient safety dangers identified through focus groups were found on checklists from safety rounds.

Most of the safety concerns compiled were equipment and communication related. Frontline staff appreciated that their concerns are heard and acted on, and leaders gained insight into quality and safety concerns of which they were not previously aware.

After 18 months, two of seven hospitals complied with the rigorous safety rounds approach. Safety climate scores

improved among all caregivers. Main safety issues by category were equipment/facility and communication.

After two years, safety rounds identified 1433 comments from 233 sessions. Most comments related to equipment and environment. Issues identifed included ambiguous assignment for resolution, lack of mechanisms for prioritisation and follow-up.

Over 8 months, staff-led safety rounds reached 182 staff from 10 disciplines. They identified 79 safety concerns, most related to equipment and care delivery (eg, need for education regarding insulin administration). 


\begin{tabular}{ll}
\hline Reference & Objectives \\
\hline Rinke et al 2008 & $\begin{array}{l}\text { Categorise three years of patient safety rounds in paediatric } \\
\text { inpatient units and nine months of paediatric surgical safety } \\
\text { rounds. }\end{array}$ \\
Tucker et al 2008 & $\begin{array}{l}\text { To contrast the safety-related concerns raised by front-line staff } \\
\text { in } 20 \text { US hospitals conducting safety rounds about hospital } \\
\text { work systems (operational failures) with national patient safety } \\
\text { initiatives. }\end{array}$ \\
Zimmerman et al 2008 & $\begin{array}{l}\text { To describe experience with and evaluation of a safety rounds } \\
\text { programme at Hamilton Health Sciences in Hamilton Ontario. }\end{array}$
\end{tabular}

To report a CEO's perspective on the experience and value of safety rounds at his hospital, Grinnell Regional Medical Center in lowa, based on 15 years of conducting them.

To describe characteristics thought to be related to patient safety within the Pediatric Emergency Care Applied Research Network, to measure staff perceptions of safety climate in EDs, and to measure associations between ED characteristics and safety climate.

To describe the weekly safety rounds programme implemented in 2005 at the North Carolina Children's Hospital.

examine and compare information gleaned from five different reporting systems within one institution: incident reporting, patient complaints, risk management, medical malpractice claims, and executive safety rounds.

To describe improvements associated with using safety rounds and briefings in Monte Naranco Hospital, a 200 bed mostly geriatric hospital.

To describe and assess the use of safety rounds at Metropolitan Hospital Center for rolling out a new strategic plan over a 2-week period to all unit/departments and shifts.

To evaluate the first phase of the Health Foundation's Safer Patients Initiative (SPI), and to identify the net additional effect of SPI and any differences in changes in participating and non-participating NHS hospitals.
Methods

Findings

Descriptive, case study.

Qualitative: classification of identified problems with comparison to objectives of national iniatives.

Descriptive with process evaluation.

Descriptive, narrative.

Quantitative: cross-sectional safety climate survey in $21 \mathrm{EDs}$ compared to survey assessing physical structure, staffing patterns, overcrowding, medication administration, teamwork, and methods for promoting patient safety.

Descriptive, case study.

Descriptive: data specific to each incident were abstracted from each system and then categorised using a common framework into one of 23 categories.

Quantitative: pre and post surveys, evaluations of leaders, interviews with frontline staff over 5 years.

Descriptive, with employee satisfaction survey.

Mixed methods: including five sub-studies using before and after comparisons of 4 intervention hospitals and 18 control hospitals in four countries in the UK National Health Service (NSH)
There were 159 completed patient safety issues; $48.4 \%$ were equipment- related, $35.8 \%$ were care coordination/records,

$7.6 \%$ were errors.

The two most frequent categories of operational failures, equipment/ supplies and facility issues, posed safety risks and diminished staff efficiency, but have not been priorities in national initiatives.

After one year of monthly safety rounds, 1,351 patient safety issues were identified, of which $64-80 \%$ were resolved or had active improvement work in progress. The process evaluation demonstrated satisfaction with safety rounds. Five areas of opportunity for process improvement were identified: scheduling, scripts, feedback, reporting and resolving issues deferred for an organisation approach.

Safety rounds provide an opportunity to conduct problem solving through coaching, to make more informed decisions, and to recognise employees.

A minority of EDs had organised safety activities, such as safety rounds (38\%). Characteristics associated with an improved safety climate were a lack of ED overcrowding, a sick call back-up plan for physicians, and the presence of an ED safety committee. Conducting safety rounds more than quarterly was not associated with higher safety climate scores. Rounds occurred weekly and 191 issues were identified during the first year, of which $58 \%$ were resolved. Senior management participates and helps staff identify solutions. Just culture and Six-Sigma help establish a culture of safety.

There was little overlap across safety systems, although each reporting system identified important safety issues. Safety rounds identified issues with equipment and supplies.

Safety rounds and briefings allowed 20\% higher number of adverse events to be detected, and are useful for Training health workers. Participants also experienced better feedback and less problems with equipment and outpatient units.

Safety rounds involved $69 \%$ of $\mathrm{MHC}$ staff, and $88.9 \%$ of management level staff and $64.5 \%$ of unionised/labour stated that they understood the hospital's new strategic plan.

The introduction of SPI1 was associated with improvements in one of the types of clinical processes studied (monitoring of vital signs) and one measure of staff perceptions of organisational climate. There was no additional effect of SPI1 on multiple other targeted issues nor on other measures of generic organisational strengthening. 
Benning et al $2011 \quad$ To evaluate the second phase of the Health Foundation's Safer Patients Initiative (SPI2) on a range of patient safety measures.

Gravenstein et al 2012

To describe a Department of Anesthesiology's experience with safety rounds involving department leaders and multiple other disciplines.

Parand et al 2012

To identify critical dimensions of hospital CEO involvement in quality improvement.

To study the implementation of a nurse-led safety rounds programme in a critical care unit over a six-month period.

Saladino et al 2013

Schwendimann 2013

To evaluate the association between safety rounds and caregiver assessments of patient safety climate and patient safety risk reduction across 49 hospitals (706 units) in a non-profit healthcare system.

Singer et al 2013

To assess the ability to refine, implement, and demonstrate the effectiveness of safety rounds in a Department of Veterans Affairs medical center by comparing 2 intervention units with 2 control units.

Taylor et al 2013

To describe the safety rounds programme at The Children's Hospital of Philadelphia implemented in 6 pilot units.

To examine the impact of a brief safety rounds programme on safety climate in the operating rooms of two tertiary care hospitals under St Luke's Medical Center administration in Quezon City, Philippines.
Using a controlled before and after design and five substudies: staff attitude survey, case notes from handwashing materials, outcomes measurement (adverse events, mortality among high-risk medical patients, patients' satisfaction, mortality in intensive care, rates of hospital-acquired infection) in 9 intervention hospitals and 9 controls in UK NHS.

Descriptive, case study with comparison of issues identified through safety rounds and other error-detection methods.

Qualitative: interviews with 17 CEOs overseeing 19 UK hospitals participating in the Safer Patient Initiative, and 36 interviews with middle managers from the same hospitals.

Mixed methods. Descriptive information and pre and post survey of unit nurses' safety climate perceptions.

Quantitative analysis using cross-sectional data to evaluate the association between participation in safety rounds and safety climate and patient safety risk reduction.

Interviews, observation, data-tracking forms, and pre and post surveys in intervention and control units to measure participant perceptions of the programme, operational benchmarks of effectiveness, and longitudinal change in safety climate.

Descriptive, case study.

Organisational climate improved in control hospitals relative to those in the intervention. Several other measures showed temporal trends but no difference between intervention and control hospitals. Mortality rates of medical patients increased in control hospitals while falling in intervention hospitals $(p=0.043)$, but this difference could not be explained by differences in preventable deaths. While there is evidence of good or improved quality and safety in NHS hospitals, authors did not detect a net effect attributable to SPI2.

Over 23 months, rounds identified 14 significant opportunities to improve care. Conventional patient experience measures and chart audits did not identify these opportunities for

improvement.

CEOs and staff identified five key roles for CEOs: (1) resource provision; (2) staff motivation and engagement; (3) commitment and support; (4) monitoring progress and (5) embedding programme elements. Findings stress the importance of safety rounds as a tool for two-way communication and demonstrating commitment.

Unit nurses' safety climate scores remained stable over the study period. Staff identified 77 safety issues and $57 \%$ were resolved during the study period.

Units with $\geq 60 \%$ of caregivers reporting exposure to at least one safety round had higher safety climate, greater patient safety risk reduction, and a higher proportion of feedback on actions taken as a result of safety rounds compared with those units with $<60 \%$ of caregivers reporting exposure.

Implementation showed fidelity to programme design, identification and resolution of issues. Senior managers' attitudes toward safety rounds were more positive than those of frontline staff, whose attitudes were mixed. Perceptions of safety climate deteriorated during the study period in the implementation units relative to controls.

The process of safety rounds was customised in each unit. In the first year, safety rounds engaged 149 individuals through 34 safety rounds. Safety rounds identified safety concerns that leaders considered previously unidentified, including

predominantly nurse-medical team relationships, workflow flaws, equipment defects, staff education, and medication safety.

Pre and postintervention surveys of OR staff nurses in both After a one-month interval, safety climate improved in the hospitals. intervention hospital (albeit no more so for those exposed to the intervention than those who were not exposed) relative to the control hospital. 
Table 1 Continued

\begin{tabular}{|c|c|c|c|}
\hline Reference & Objectives & Methods & Findings \\
\hline Lim et al 2014 & $\begin{array}{l}\text { To evaluate the effectiveness of a safety rounds programme in } \\
\text { improving the patient safety culture in Tan Tock Seng Hospital, } \\
\text { Singapore. }\end{array}$ & $\begin{array}{l}\text { Mixed methods: including evaluation of documents, } \\
\text { protocols, meeting minutes, Post-test surveys, action plans } \\
\text { and verbal feedback over } 7 \text { years. }\end{array}$ & $\begin{array}{l}321 \text { issues were identified during the study period, of which } \\
308(96.0 \%) \text { issues had been resolved. Issues related to work } \\
\text { environment were most common ( } 45.2 \%) ; 72.9 \% \text { of issues } \\
\text { identified were not identified through other conventional } \\
\text { methods of error detection. Most survey participants reported } \\
\text { increased awareness of patient safety }(94.8 \%) \text { and comfort in } \\
\text { openly and honestly discussing patient safety issues }(90.2 \%) \text {. }\end{array}$ \\
\hline Marck et al 2014 & $\begin{array}{l}\text { To explore perceptions of safety and quality in one } \\
\text { haemodialysis unit using participatory photographic research } \\
\text { methods. }\end{array}$ & $\begin{array}{l}\text { Qualitative: Practitioners conducted a safety round to obtain } \\
\text { photographs of patient care unit and nurses' stories (photo } \\
\text { narration) about safety and quality issues identified through } \\
\text { an initial focus group. Applied iterative coding, then used } \\
\text { photos to elicit more input about themes in a second focus } \\
\text { group with additional staff. }\end{array}$ & $\begin{array}{l}\text { The major themes identified related to clutter, infection } \\
\text { control, unit design, chemicals and air quality, lack of storage } \\
\text { space, and health and safety hazards. The visual methods } \\
\text { engaged researchers and unit nurses in rich dialogue about } \\
\text { safety in this complex environment, and provides an ongoing } \\
\text { basis for monitoring and enhancing safety. }\end{array}$ \\
\hline Martin et al 2014 & $\begin{array}{l}\text { To explore how safety rounds are used in practice in multiple } \\
\text { facilities participating in the English NHS, and to identify } \\
\text { variations in implementation that might mediate their impact } \\
\text { on safety and culture. }\end{array}$ & $\begin{array}{l}\text { Qualitative: interviews ( } 82 \text { individuals); analysis using } \\
\text { constant comparative method. }\end{array}$ & $\begin{array}{l}\text { Modification and expansion of safety rounds to increase the } \\
\text { scope of knowledge produced increased the value that } \\
\text { executives drew from them, but replaced the objectives of } \\
\text { identifying specific, actionable knowledge about safety issues } \\
\text { and a more positive safety culture and relationship between } \\
\text { senior managers and frontline staff with a form of surveillance } \\
\text { that alienated frontline staff and produced fallible insights. }\end{array}$ \\
\hline Profit et al 2014 & $\begin{array}{l}\text { To examine the relationship between safety rounds, caregiver } \\
\text { assessments of patient safety culture, and healthcare worker } \\
\text { burnout in } 44 \text { neonatal intensive care units. }\end{array}$ & $\begin{array}{l}\text { Quantitative: cross-sectional survey evaluating the } \\
\text { association between receiving feedback about actions taken } \\
\text { as a result of safety rounds and healthcare worker } \\
\text { assessments of patient safety culture at an individual level. }\end{array}$ & $\begin{array}{l}\text { With } 63 \% \text { survey response, more safety round feedback was } \\
\text { associated with better safety culture results, and lower burnout } \\
\text { rates in the NICUs. Participation in safety rounds and receiving } \\
\text { feedback about safety rounds were less common in NICUs } \\
\text { than in a benchmarking comparison of adult clinical areas. }\end{array}$ \\
\hline Rotteau et al 2014 & $\begin{array}{l}\text { To explore views and experiences of safety rounds in two } \\
\text { major teaching hospitals with mature safety rounds } \\
\text { programmes. }\end{array}$ & $\begin{array}{l}\text { Qualitative: interviews with } 11 \text { senior leaders and } 33 \\
\text { frontline staff, collected as part of a larger mixed-methods } \\
\text { evaluation. }\end{array}$ & $\begin{array}{l}\text { Senior leaders regarded executive visibility as an end in itself, } \\
\text { and generally did not engage with staff concerns beyond the } \\
\text { safety rounds encounter. Some senior leaders believed they } \\
\text { understood patient safety issues better than frontline staff and } \\
\text { even characterised staff concerns as 'stupid'. Senior leaders } \\
\text { acknowledged that they often controlled the conversations, } \\
\text { delimiting what counted as patient safety problems, and } \\
\text { steered conversations to predetermined topics. }\end{array}$ \\
\hline Tucker and Singer 2014 & $\begin{array}{l}\text { To rigorously examine the impact of safety rounds on } \\
\text { organisational outcomes. }\end{array}$ & $\begin{array}{l}\text { Mixed methods. Randomised controlled trial involving } 20 \\
\text { intervention hospitals and } 56 \text { work areas; quantitative } \\
\text { analysis examining problem resolution and problem-solving } \\
\text { approach and qualitative analysis of interviews and } \\
\text { observations to explore negative results. }\end{array}$ & $\begin{array}{l}\text { After } 18 \text { months, on average, safety rounds had a negative } \\
\text { impact on performance. Prioritising easy-to-solve problems was } \\
\text { associated with improved performance, likely because it } \\
\text { resulted in greater action-taking. Prioritising high-value } \\
\text { problems was not successful. Assigning to senior managers } \\
\text { responsibility for ensuring that identified problems get resolved } \\
\text { also resulted in better performance. }\end{array}$ \\
\hline
\end{tabular}


Methodological limitations of prior research on the efficacy of safety rounds

Most of the studies that report positive results have methodological limitations, such as reporting on a single organisation's implementation of the programme, lack of control groups, ${ }^{36} 4045$ lack of objective performance measures to verify the improvement and self-selection for programme implementation. In particular, self-selection limits generalisability of the findings because organisations that voluntarily embark on a programme of safety rounds might differ from other organisations in ways that effect implementation success. Furthermore, to validate their decision to implement the programme, the organisations might be predisposed to view the outcomes from the safety rounds programme in a positive light. Or, organisations with less positive experiences of safety rounds may choose not to invest the effort in reporting their results, given the difficulty of getting null results published. Finally, most papers reflect the perspective of the hospital personnel responsible for implementing safety rounds. Including a broader set of perspectives might provide more nuanced results. For example, three studies that use in-depth interviews to explore the impact of safety rounds on frontline staff find that safety rounds negatively impact individuals who participate in the rounds. ${ }^{32} 5657$

A subset of 14 papers empirically examines the effect of safety rounds using survey measures of safety climate or safety or quality performance. Eight of these report positive outcomes stemming from safety rounds, such as higher perceptions of safety climate, ${ }^{23} 38{ }^{58-60}$ detection of more adverse events, ${ }^{42}$ greater patient safety risk reduction, ${ }^{58}$ higher job satisfaction $^{37}$ and lower burnout, ${ }^{33}$ which is linked to safety culture in a paper recently published in this journal. $^{61}$

However, some studies, including the three with the most rigorous research methods, suggest less sanguine results. Two experimental controlled studies, one in the US Veterans Health Administration ${ }^{55}$ and the other in the private sector, ${ }^{62}$ find that safety climate and perceived improvement in performance decline in randomly selected intervention units compared to control units and hospitals. The third experimental study, in which safety rounds were implemented as part of a general improvement programme, shows some improvement in organisational climate relative to control hospitals, but no improvement or a relative decline in multiple other measures. ${ }^{46} 63$ A fourth, uncontrolled study similarly finds that safety climate remains unchanged after a six-month programme that includes safety rounds. ${ }^{64}$ Another study uses crosssectional data from 21 paediatric emergency departments (ED) and finds that conducting monthly safety rounds is not associated with higher safety climate scores. ${ }^{65}$

\section{KEYS TO SUCCESSFUL IMPLEMENTATION}

The mixed results of safety rounds suggest that implementation differences may drive their success. Indeed, several papers identify possible determinants of successful implementation, including factors related to the breadth of exposure of staff to safety rounds, characteristics of hospital leaders, willingness of frontline workers to speak up, adequacy of the infrastructure for implementing and sustaining the programme, and the specific type of safety rounds programme being implemented.

\section{Intensity of exposure to safety rounds}

Several studies find that higher levels of exposure-a higher proportion of staff who have participated in safety rounds, substantial engagement with senior managers during a safety round visit, and the receipt of feedback about actions taken as a result-correlate with better outcomes. In a study of 49 hospitals, Schwendimann and colleagues find that staff-rated safety climate is higher in units where at least 60\% of staff report participating in safety rounds. ${ }^{58}$ However, only $7.4 \%$ of hospital units in their study achieve exposure at this threshold. Consistent with this finding, in Thomas and colleagues' study, which measures the impact of safety rounds on individual nurses, safety climate only increases for those nurses who participate in a safety round visit. $^{60}$ Similarly, while Frankel and colleagues observe improvement in safety climate perceptions, improvement occurs only in the two of seven hospitals that sustained the safety rounds programme. $^{23}$

This evidence of a dose-response relationship suggests that safety rounds should involve as many staff as possible. The optimistic notion that positive frontline staff perceptions of safety climate can be spread via positive word-of-mouth from peers who participate in safety rounds does not appear to be supported. Thus, to have a beneficial effect, managers must commit to the time-consuming work of visiting with as many frontline staff as possible, which, in practice probably means visiting a given unit more than, say, once a year. However, several papers comment on the difficulty of sustaining a schedule of frequent safety rounds, ${ }^{23} 36$ even if rounds are conducted by department managers and frontline staff rather than executives. $^{45^{\circ}}$

\section{Senior managers' understanding and engagement with safety rounds}

Successful implementation requires 'significant organisational will'. ${ }^{23}$ Leaders must engage actively in the safety rounds programme and assume accountability for ensuring resolution of issues and reporting back to frontline workers. ${ }^{18} \quad 41 \quad 62 \quad 66$ When conducting rounds, leaders need to listen attentively to gain deeper understanding of the issues that their organisations face. ${ }^{18} 27^{55}$ Less successful implementation 
stems from the inability of leaders to connect with frontline staff during rounds ${ }^{46}$ or divergence of leaders' motives for implementing the programme from the original intent of safety rounds. For example, studies from the USA, UK and Germany report that some managers use safety rounds as a form of surveillance and control rather than inquiry and support. ${ }^{55-57}$ Some senior managers regard safety rounds as an end in themselves, without engaging in action to resolve staff concerns ${ }^{32}{ }^{62}$ - they want to demonstrate to frontline staff that they care about their concerns without committing to address those concerns. Other studies report instances of managers believing they understand patient safety issues better than frontline staff ${ }^{32} 55$ and controlling and restricting conversations during safety rounds to avoid topics they do not want to discuss. ${ }^{32}$ Organisations also spend too much time focusing on prioritising problems at the expense of taking action. ${ }^{62}$ When safety rounds are characterised in these ways, frontline workers become frustrated with them, ${ }^{32}{ }^{55}$ feel the programme produces fallible insights ${ }^{55} 57$ and respond with scepticism and cynicism. ${ }^{56} 62$

\section{Willingness of frontline workers to speak up}

Safety rounds are more successful when frontline staff members openly discuss safety issues in their work areas. ${ }^{39} 41$ This is more likely to occur when the hospital has a just culture. ${ }^{67}{ }^{68}$ Frontline staff are also more likely to participate when they perceive the programme is adding value, ${ }^{48}$ as evidenced through constructive actions taken to resolve the problems that challenge them. ${ }^{39}{ }^{62} \mathrm{~A}$ few studies suggest the importance of physician involvement in making safety rounds successful ${ }^{67}$ or a lack thereof being potentially problematic. $^{55}$

\section{Ability to execute and follow-up on safety rounds}

Supportive infrastructure also seems key, including strong project management, ${ }^{23} 39$ scheduling capability, ${ }^{39} 45$ availability of tailored scripts to enable a productive discussion with frontline staff during safety rounds, ${ }^{45}$ maintaining an effective database to monitor action-taking and formal processes to ensure follow-up. ${ }^{27} 4866$ Middle managers provide critical support for safety rounds ${ }^{39} 55$ as well as implementation practices that include application of analytical tools for understanding the problem, small tests of change, and communication, feedback and celebration of results. $434548 \quad 66-68$

\section{VARIATIONS OF SAFETY ROUNDS THAT REQUIRE FURTHER STUDY}

\section{Adopt-a-unit}

Several studies describe safety rounds programmes whose structural design diverges in potentially useful ways. The most widely used of these may be the senior executive adopt-a-work unit programmes, which is a component of the Comprehensive Unit-Based Safety Program. In the adopt-a-unit programme, managers support a unit on a continuing basis rather than rotating among units. ${ }^{41}$ Relatedly, several studies report on a department or unit-level implementation of safety rounds rather than a hospital-wide implementation. We found safety rounds papers for radiology, ${ }^{43}$ intensive care unit, ${ }^{52}$ $\mathrm{ED}^{65}$ and anaesthesia ${ }^{53}$ applications. In a notable departure from the 'quick fix' type of issues typically identified through safety rounds, a paper reporting on radiology safety rounds conducted by radiology leaders highlights 10 substantial process changes that come from the programme. ${ }^{43}$ Solving these problems required several iterations of problem-solving cycles to redesign the department's processes. It may be that focusing on a single unit enables deeper problem solving than safety rounds programmes that rotate among different units in the hospital.

\section{Safety rounds as part of more comprehensive or narrowly focused programmes}

A second variant is the use of safety rounds as part of comprehensive surveillance programmes ${ }^{47}$ or as a feature of multifaceted programmes to improve the reliability of clinical care processes. ${ }^{34}$ These studies find that safety rounds provide a unique source of information that complements other safety initiatives, and that relying solely on safety rounds would hamper safety-related information and performance. Another variation involves rounding for communicating information about specific issues, such as a new strategic plan, rather than inquiring generally about safety concerns. ${ }^{69}$ This study finds that rounding by senior managers is an effective method for disseminating information to frontline staff.

\section{Other staff can 'walk around'}

Finally, some studies investigate rounding by frontline staff $^{49} 70$ or department managers ${ }^{45}$ rather than senior managers. In one case, providers use photographs to elicit deeper discussion among other staff members about what was observed on safety rounds. ${ }^{70}$ Though clearly serving a purpose other than increasing senior managers' knowledge and engagement with frontline staff, these studies suggest that safety rounds can be successfully used to identify safety hazards on the frontlines, even if they are not led by senior managers.

\section{SAFETY ROUNDS CAN IMPROVE SAFETY CULTURE, BUT MUST BE IMPLEMENTED WITH CARE}

The existing literature suggests that safety rounds can effectively improve culture, address specific safety problems and increase managers' understanding of safety risks as well as their commitment to addressing them. Successful programmes have been deployed in a wide 
variety of hospital types, departments, clinical disciplines and geographic locations.

However, poor implementation of safety rounds produces no improvement and can even worsen safety culture. Research shows that when organisations implement safety rounds for the purpose of surveillance or in a superficial manner, it can hurt safety culture by exposing the senior managers' lack of respect for the frontline staff's input and their lack of commitment to addressing safety concerns. Effective implementation requires senior leadership's commitment to implementing safety rounds as a way of gathering useful information about their organisations' safety risks, widespread participation of frontline staff in the safety rounds, inclusion of middle managers and follow-up on the issues that are raised. Given that openly questioning and actively listening to frontline workers appears unnatural for many senior managers, ${ }^{32} 5557$ training ${ }^{71}$ and coaching may be productive strategies for improving the performance of safety rounds.

\section{FUTURE RESEARCH}

Much remains to be discovered about safety rounds. Few studies have gathered objective safety measures. A notable exception is the study by Donnelly et $a l^{43}$ which finds that the mean number of days between safety events doubled after the implementation of radiology safety rounds. Furthermore, to our knowledge, no studies collected data on the financial costs and benefits of such programmes. Hospital executives have limited time to devote to improvement activities. ${ }^{39}$ Whether there are other interventions that can improve safety culture more efficiently remains to be seen. Further research could also more closely examine the impact of varied safety rounds experiences on senior managers' understanding of safety risks. It may be that managers benefit from observing a wide variety of locations and clinical disciplines or, alternatively, that they benefit more from focused safety rounds that create a deeper connection with and understanding of that specialty. Research could compare whether the managers' background, particularly their status as clinicians or non-clinicians, moderates the impact of variety in safety rounds experience.

\section{CONCLUSION}

It is evident that hospital executives want tangible ways they can make their hospitals safer places for patients. The idea of senior managers walking around and talking to staff has obvious appeal and appears like a simple enough intervention: go talk to staff where they work, listen to what the staff have to say and fix a few problems they point out. However, this simplistic view is misleading. Safety rounds can lead to improved culture, but only when they are implemented authentically and with full commitment and ability to resolve frontline staff's concerns. Half-hearted, insincere or ineffective safety rounds can backfire, eroding rather than improving safety culture and wasting time at all levels of the organisation. Organisations interested in implementing safety rounds are well advised to develop process improvement capabilities first ${ }^{71}$, or to begin in one or two units, rather than tackling the entire organisation. Senior managers not inclined to invest the time and effort to solicit, really listen and address frontline staff's concerns, may want to focus on other means to improve their organisation's culture. Despite the term 'walk rounds', implementing safety rounds is no walk in the park; but then again, improving organisational culture never is.

Contributors Both authors made substantial contributions to the conception and design of the work and the analysis and interpretation of our findings. The authors also contributed to drafting the paper and revising it critically for important intellectual content. The authors have given final approval of the version to be published and agree to be accountable for all aspects of the work in ensuring that questions related to the accuracy or integrity of any part of the work are appropriately investigated and resolved.

Competing interests SJS acknowledges writing three of the papers reviewed in this editorial. ALT acknowledges writing two of the papers reviewed in this editorial.

Provenance and peer review Not commissioned; internally peer reviewed.

\section{REFERENCES}

1 Clarke $S$. The relationship between safety climate and safety performance: a meta-analytic review. J Occup Health Psychol 2006;11:315-27.

2 Schein EH. Organizational Culture and Leadership. 2nd edn. San Francisco: Jossey-Bass, 1992.

3 Singer SJ, Vogus TJ. Reducing hospital errors: interventions that build safety culture. Annu Rev Public Health 2013;34:373-96.

4 Zohar D. Safety climate in industrial organizations: theoretical and applied implications. J Appl Psychol 1980;65:96-102.

5 Birkmeyer NJON, Finks JFJ, Greenberg CKC, et al. Safety culture and complications after bariatric surgery. Ann Surg 2013;257:260-5.

6 Gershon RR, Karkashian CD, Grosch JW, et al. Hospital safety climate and its relationship with safe work practices and workplace exposure incidents. Am J Infect Control 2000;28:211-21.

7 Hansen L, Williams M, Singer S. Perceptions of hospital safety climate and incidence of readmission. Health Serv Res 2010;42:596-616.

8 Hofmann DA, Mark B. An investigation of the relationship between safety climate and medication errors as well as other nurse and patient outcomes. Personnel Psychol 2006;59:847-69.

9 Huang DT, Clermont G, Kong L, et al. Intensive care unit safety culture and outcomes: a US multicenter study. Int J Qual Health Care 2010;22:151-61.

10 McFadden KL, Henagan SC, Gowen CR. The patient safety chain: transformational leadership's effect on patient safety culture, initiatives, and outcomes. J Operations Manag 2009;27:390-404.

11 Rosen A, Singer S, Zhao S, et al. Hospital safety climate and safety outcomes: is there a relationship in the VA? Med Care Res Rev 2010;67:590-608. 
12 Singer SJ, Lin S, Falwell A, et al. Relationship of safety climate and safety performance in hospitals. Health Serv Res 2009;44:399-421.

13 Steyrer J, Schiffinger M, Huber C, et al. Attitude is everything? The impact of workload, safety climate, and safety tools on medical errors: a study of intensive care units. Health Care Manage Rev 2013;38:306-16.

14 Valentin A, Schiffinger M, Steyrer J, et al. Safety climate reduces medication and dislodgement errors in routine intensive care practice. Intensive Care Med 2012;39: 391-8.

15 Vogus TJ, Sutcliffe KM. The Safety Organizing Scale: development and validation of a behavioral measure of safety culture in hospital nursing units. Med Care 2007;45:46-54.

16 Wua T-C, Chenb C-H, Lib C-C. A correlation among safety leadership, safety climate and safety performance. J Loss Prev Process Ind 2008;21:307-18.

17 Zohar D, Livne Y, Tenne-Gazit O, et al. Healthcare climate: a framework for measuring and improving patient safety. Crit Care Med 2007;35:1312-17.

18 Parand A, Dopson S, Vincent C. The role of chief executive officers in a quality improvement: a qualitative study. BMJ Open 2013;3:e001731.

19 Singer SJ, Falwell A, Gaba DM, et al. Patient safety climate in US hospitals: variation by management level. Med Care 2008;46:1149-56.

20 Pronovost PJ, Weast B, Holzmueller CG, et al. Evaluation of the culture of safety: survey of clinicians and managers in an academic medical center. Qual Saf Health Care 2003;12:405-10.

21 Hartmann CW, Rosen AK, Meterko M, et al. An overview of patient safety climate in the VA. Health Serv Res 2008;43:1263-84.

22 Womack J. Gemba walks. Lean Enterprises Institute, Incorporated. 2011.

23 Frankel A, Pratt Grillo S, Pittman M, et al. Revealing and resolving patient safety defects: the impact of leadership walkrounds on frontline caregiver assessments of patient safety. Health Serv Res 2008;43:2050-66.

24 Frankel A, Gandhi T, Bates D. Improving patient safety across a large integrated health care delivery system. Int J Qual Health Care 2003;15:i31-40.

25 Peters TJ, Waterman RH. In search of excellence: lessons from America's best-run companies. New York: Harper \& Row, Publishers, Inc., 1982.

26 Eubanks P. CEO walkabouts get firsthand look at employee problems. Hospitals 1990;64:50-1.

27 Frankel A, Grillo S, Baker E, et al. Patient safety leadership walkrounds at partners healthcare: learning from implementation. Jt Comm J Qual Patient Saf 2005;31:423-37.

28 Institute for Healthcare Improvement. Patient safety leadership walkrounds. Boston, 2004.

29 National Patient Safety Agency. Patient safety first: 2008-2010, The campaign review. London, 2011.

30 Weaver SJ, Lubomksi LH, Wilson RF, et al. Promoting a culture of safety as a patient safety strategy: a systematic review. Ann Intern Med 2013;158:369-74.

31 Morello RT, Lowthian JA, Barker AL, et al. Strategies for improving patient safety culture in hospitals: a systematic review. BMJ Qual Saf 2013;22:11-18.

32 Rotteau L, Shojania KG, Webster F. 'I think we should just listen and get out': a qualitative exploration of views and experiences of Patient Safety Walkrounds. BMJ Qual Saf 2014;23:823-9.
33 Sexton JB, Sharek PJ, Thomas EJ, et al. Exposure to Leadership WalkRounds in neonatal intensive care units is associated with a better patient safety culture and less caregiver burnout. BMJ Qual Saf 2014;23:814-22.

34 Burnett S, Parand A, Benn J, et al. Learning about leadership from patient safety walkrounds ${ }^{\mathrm{TM}}$. Int J Clin Leadersh 2008;16:185-92.

35 Frankel A. WalkRounds improve patient safety. Gaining feedback to provide exceptional patient care. Healthc Exec 2008;23:22-7.

36 Linden TC. The value of WalkRounds: using WalkRounds to lead more effectively. Healthc Exec 2009;24:76-8.

37 Anonymous. Walkrounds boost safety and satisfaction. Health Care Strateg Manage 2005;23:12.

38 Lim RBT, Ng BBL, Ng KM. Evaluation of the patient safety Leadership Walkabout programme of a hospital in Singapore. Singapore Med J 2014;55:78-83.

39 Budrevics G, O'Neill C. Changing a culture with patient safety walkarounds. Healthc Q 2005;8:20-5.

40 Feitelberg SP. Patient safety executive walkarounds. Perm J 2006;10:29-36.

41 Pronovost P, Weast B, Bishop K, et al. Senior executive adopt-a-work unit: a model for safety improvement. Jt Comm J Qual Saf 2004;30:59-68.

42 Menendez MD, Martinez AB, Fernandez M, et al. Walkrounds and briefings in the improvement of the patient safety. Revista De Calidad Asistencial 2010;25:153-60.

43 Donnelly LF, Dickerson JM, Lehkamp TW, et al. IRQN award paper: Operational rounds: a practical administrative process to improve safety and clinical services in radiology. J Am Coll Radiol 2008;5:1142-9.

44 Tucker AL, Singer SJ, Hayes JE, et al. Front-line staff perspectives on opportunities for improving the safety and efficiency of hospital work systems. Health Serv Res 2008;43:1807-29.

45 Zimmerman R, Ip I, Daniels C, et al. An evaluation of patient safety leadership walkarounds. Healthc Q 2008;11: $16-20$.

46 Benning A, Ghaleb M, Suokas A, et al. Large scale organisational intervention to improve patient safety in four UK hospitals: mixed method evaluation. BMJ 2011;342:d195.

47 Levtzion-Korach O, Frankel A, Alcalai H, et al. Integrating incident data from five reporting systems to assess patient safety: making sense of the elephant. Jt Comm J Qual Patient Saf 2010;36:402-10.

48 Matlow A, Stevens P, Urmson L, et al. Improving patient safety through a multi-faceted internal surveillance program. Healthc Q 2008;11:101-8

49 Montgomery VL. Impact of staff-led safety walk rounds. 2008; retrieved 26 June 2014.

50 Taylor AM, Chuo J, Figueroa-Altmann A, et al. Using Four-Phased Unit-Based Patient Safety Walkrounds to Uncover Correctable System Flaws. Jt Comm J Qual Patient Saf 2013;39:369-403.

51 Rinke ML, Zimmer KP, Lehmann CU, et al. Patient safety rounds in a pediatric tertiary care center. Jt Comm J Qual Patient Saf 2008;34:5-12.

52 Elder NC, Brungs SM, Nagy M, et al. Intensive care unit nurses' perceptions of safety after a highly specific safety intervention. Qual Saf Health Care 2008;17:25-30.

53 Gravenstein D, Ford S, Enneking FK. Anesthesiology leadership rounding: identifying opportunities for improvement. Perm J 2012;16:37-40. 
54 Taylor MJ, McNicholas C, Nicolay C, et al. Systematic review of the application of the plan-do-study-act method to improve quality in healthcare. BMJ Qual Saf 2014;23:290-8.

55 Singer SJ, Rivard PE, Hayes JE, et al. Improving Patient Care Through Leadership Engagement with Frontline Staff: A Department of Veterans Affairs Case Study. Jt Comm J Qual Patient Saf 2013;39:349-60.

56 Beil-Hildebrand $\mathrm{M}$. The implications of management by walking about: a case study of a German hospital. Leadersh Health Serv 2006;19:i-xv.

57 Martin G, Ozieranski P, Willars J, et al. Walkrounds in practice: corrupting or enhancing a quality-improvement intervention? A qualitative study. Jt Comm J Qual Patient Saf 2014;40:303-10.

58 Schwendimann R, Milne J, Frush K, et al. A closer look at associations between hospital leadership walkrounds and patient safety climate and risk reduction: a cross-sectional study. Am J Med Qual 2013;28:414-21.

59 Chua ME, Luna SL. Assessing the effects of executive WalkRounds on safety climate attitudes in the OR setting at a tertiary hospital. Am J Med Qual 2014;29:260-1.

60 Thomas EJ, Sexton JB, Neilands TB, et al. The effect of executive walk rounds on nurse safety climate attitudes: a randomized trial of clinical units. BMC Health Serv Res 2005;5:28-36.

61 Profit J, Sharek PJ, Amspoker AB, et al. Burnout in the NICU setting and its relation to safety culture. BMJ Qual Saf 2014;23:806-13.

62 Tucker AL, Singer SJ. The effectiveness of management-by-walking-around: a Randomized Field Study. Prod Operations Manag. Published Online First: 31 March 2014. doi:10.1111/poms.12226
63 Benning A, Dixon-Woods M, Nwulu U, et al. Multiple component patient safety intervention in English hospitals: controlled evaluation of second phase. BMJ 2011;342:d199.

64 Saladino L, Pickett LC, Frush K, et al. Evaluation of a nurse-led safety program in a critical care unit. J Nurs Care Qual 2013;28:139-46.

65 Shaw KN, Ruddy RM, Olsen CS, et al. Pediatric patient safety in emergency departments: unit characteristics and staff perceptions. Pediatrics 2009;124:485-93.

66 Gandhi T, Graydon-Baker E, Huber C, et al. Closing the loop: follow-up and feedback in a patient safety program. Jt Comm J Qual Patient Saf 2005;31:614-21.

67 Graham S, Brookey J, Steadman C. Patient Safety Executive Walkarounds. In: Henriksen K, Battles JB, Marks ES, et al., eds. Advances in Patient Safety. Rockville, MD: Agency for Healthcare Research and Quality (US), 2005;223-35.

68 Yee PL, Edwards ML, Dixon J, et al. Implementation of patient safety rounds in a children's hospital. Nurs Adm Q 2009;33:48-53.

69 Rubin MS, Stone RK. Adapting the "managing by walking around" methodology as a leadership strategy to communicate a hospital-wide strategic plan. J Public Health Manag Pract 2010;16:162-6.

70 Marck P, Molzahn A, Berry-Hauf R, et al. Exploring safety and quality in a hemodialysis environment with participatory photographic methods: a restorative approach. Nephrol Nurs J 2014;41:25-35; quiz36.

71 Richardson S, Watson S, Wrong T, et al. Implementing leadership rounds to improve patient safety. Health Manage Forum 2007;20:38-41; quiz36. 